\title{
AKULTURASI ARSITEKTUR KOLONIAL BELANDA PADA RUMAH TOKO CINA PERANAKAN DI JAKARTA
}

\author{
Christianto Roesli; Sri Rachmayanti \\ Interior Design Department, School of Design, BINUS University \\ Jln. K.H. Syahdan No. 9, Palmerah, Jakarta Barat 11480 \\ roeslichris@gmail.com
}

\begin{abstract}
Indonesia is a nation consisting of various ethnicities, races, and cultures. It is because the location of the Indonesian archipelago was in the traffic trade in the early days of the 5th century $A D$. Chinese ethnic is one ethnicity that already has had a relationship with the Southeast Asian region. In the 19th century shop houses were spread in the coastal areas and concentrated only in the Chinatown. Research used qualitative method with a historical approach. Data were obtained from a variety of literature, both journal articles, books, and the Internet. The results show that in the beginning the shop houses were built by the colonial government to implement a plot system such in the Europe. However, by the influence of the Chinese descendants, limited land with a high population density makes the system become a clever problem solving. Acculturation is a process that refers to the cultural and psychological changes due to encounters with culturally different people. This process allows culture and ethnic groups adapt to another culture. Research concludes that shop house can be seen as a result of Chinese descendants and Dutch acculturation existing in the coastal cities of Indonesia.
\end{abstract}

Keywords: acculturation, shop house, Chinese descendants

\begin{abstract}
ABSTRAK
Indonesia merupakan suatu bangsa yang terdiri dari berbagai etnis, ras, dan budaya. Hal itu disebabkan letak kepulauan Indonesia berada di lalu lintas perdagangan pada masa-masa awal abad ke-5 Masehi. Etnis Cina merupakan salah satu etnis yang sudah mempunyai hubungan dengan kawasan Asia Tenggara. Pada abad ke-19 rumah toko tersebar di daerah pesisir dan terpusat hanya di daerah pecinan. Penelitian menggunakan metode kualitatif dengan pendekatan historis. Data diperoleh dari beragam literatur baik artikel jurnal, buku, maupun Internet. Hasil menunjukkan bahwa pada mulanya rumah toko dibangun oleh pemerintah kolonial dengan menerapkan sistem kavling seperti di Eropa. Namun dengan pengaruh cina peranakan, lahan yang terbatas dengan kepadatan penduduk tinggi membuat sistem ini menjadi pemecahan masalah yang cerdik. Akulturasi adalah suatu proses yang merujuk pada perubahan budaya dan psikologis karena perjumpaan dengan orang yang beda budaya. Proses ini memungkinkan budaya dan kelompok etnis menyesuaikan diri dengan budaya yang lain. Penelitian menyimpulkan rumah toko dapat dilihat sebagai hasil akulturasi budaya cina peranakan dan Belanda yang ada di kota-kota pesisir Indonesia.
\end{abstract}

Kata kunci: akulturasi, rumah toko, cina peranakan 


\section{PENDAHULUAN}

Kajian arsitektur dengan pengaruh tradisi Cina, India, Timur Tengah hingga negara Barat memberikan warna tersendiri bagi bangunan-bangunan peninggalan masa lalu di Nusantara. Menelusuri peninggalan abad ke-19 di Batavia dengan langgam Cina menunjukkan kuatnya tradisi negara asal di bumi Nusantara. Letak kawasan pesisir Nusantara di daerah lalu lintas perdagangan menjadikan kawasan di Nusantara sebagai kawasan yang cukup banyak mendapat pengaruh kaum pendatang. Tiada tempat di belahan dunia ini yang tidak tersentuh oleh ekspansi kekaisaran Cina, dan kawasan Asia Tenggara merupakan kawasan yang paling erat dan secara berkesinambungan disebut dalam catatan sejarah mereka dengan sebutan Nanyang atau Laut Selatan (Knapp, 2010).

Orang Cina sudah terdapat di pesisir utara pulau Jawa, terutama di Jawa Barat, bahkan jauh sebelum Belanda datang. Mungkin tidak perlu untuk menelusuri sampai ekspedisi Cheng Ho (Zheng He) yang menyebarkan ajaran Islam di pelabuhan-pelabuhan Jawa Timur. Dapat dilihat bahwa dari data dapat diketahui bahwa pada abad ke-16 banyak orang Cina yang sudah tinggal di Banten. Menarik bagaimana orang-orang Cina menyebut Batavia sebagai Ye-cheng artinya kota Kelapa yang merupakan terjemahan dari nama lama, yakni Sunda Kelapa (Salmon \& Lombard, 1985).

Kota-kota pantai Indonesia berkembang menjadi kota-kota perniagaan. Sebagaimana umumnya sebuah kota perniagaan, maka daerah pesisir ini menjadi tujuan para pedagang dari seluruh dunia untuk melakukan aktivitas perdagangan. Pada akhirnya mereka mulai menetap dan membentuk lingkungan hunian di daerah tujuan tersebut.

\section{METODE}

Penelitian menggunakan metode kualitatif. Penelitian memakai pendekatan historis melalui interdisplin ilmu seperti Antropologi, Sosiologi, Arsitektur, dan Desain. Data diperoleh dari literatur yang bersumber dari artikel jurnal, buku, majalah, Internet, dan foto dokumentasi pribadi.

\section{HASIL DAN PEMBAHASAN}

Kondisi memungkinkan terjadi akulturasi kebudayaan yang memberikan kekayaan arsitektur pada kota-kota pesisir di Indonesia. Kondisi diakibatkan oleh beragamnya kelompok etnis yang pada dasarnya membawa unsur-unsur kebudayaan dari daerah asal. Jakarta yang dikenal sebagai Batavia juga merupakan kota pesisir yang berkembang menjadi kota perniagaan besar. Terbentuknya daerahdaerah etnis diakibatkan oleh peraturan yang dibuat oleh pemerintah Belanda yang mengotakngotakkan etnis sesuai dengan asalnya seperti etnis Cina, Arab, Belanda, serta pribumi.

Orang-orang Tionghoa yang bermigrasi ke Indonesia berasal dari provinsi di Cina Selatan (Guandong, Fujian). Mereka mayoritas berasal dari kalangan pekerja (buruh, petani, nelayan, dan sebagainya). Para pedagang ini melakukan perjalanan ke kawasan Asia Tenggara, dalam hal ini Batavia, dapat berbulan-bulan menetap di kota-kota pesisir yang diakibatkan pergantian musim. Hal tersebut menimbulkan permasalahan tersendiri, seperti aspek-aspek norma, kultur, psikologi yang jauh berbeda dengan daerah asal dibandingkan karakteristik daerah tempat mereka menetap sementara. Keadaan geografis turut memengaruhi karakteristik bentuk bangunan sebagai wujud dari sebuah karya budaya. 
Kawasan Asia Tenggara dapat dikatakan merupakan kawasan pertemuan serta lalu lintas pelayaran dan perdagangan, sehingga banyak dipengaruhi oleh berbagai pengaruh luar baik dari India, Arab, Cina, Eropa, Jepang. Semua pengaruh tersebut dengan damai serta harmoni diserap oleh kebudayaan lokal. India dan Cina sebagai peradaban yang dominan memengaruhi kota-kota pesisir di kawasan Asia Tenggara. Kapal-kapal dari Utara (Cina, Jepang, Ryukyu) berlayar ke selatan dipengaruhi oleh angin Monsun Utara yang berhembus dari Januari - Februari dan kembali ke daerah asal pada saat berhembus angin Monsun Selatan (Juni - Agustus).

Sedangkan kapal-kapal India berlayar ke Timur dipengaruhi oleh angin Monsun Barat Daya antara bulan April-Agustus dan kembali dengan memanfaatkan angin Monsun Timur Laut pada bulanbulan Desember. Selama masa angin topan dan pancaroba, para pedagang menetap di kota-kota pesisir tersebut, sambil menunggu rekan bisnis mereka datang dari tempat-tempat yang lain. Dalam masa tersebut mereka berinteraksi dan bercampur dengan penduduk lokal setempat. (Widodo, 2004)

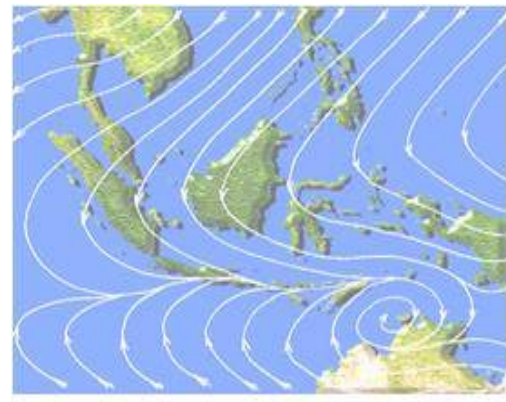

A. Musim Hujan

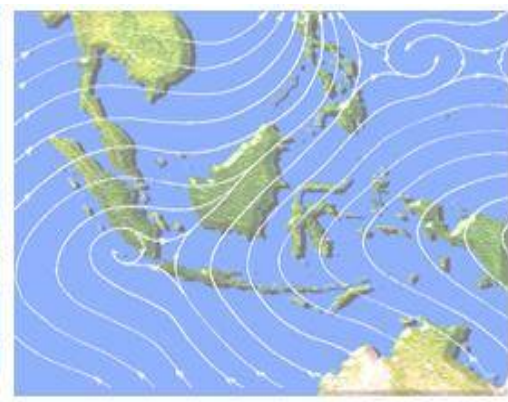

B. Musim Kemarau

Gambar 1 Pergerakan Angin Monsun Sepanjang Tahun di Kawasan Asia Tenggara

(Sumber: Stamet Ahmad Yani Semarang, n.d.)

Rumah Toko (Ruko) dapat dikatakan merupakan bangunan yang khas pecinan. Khol (1984) yang banyak mengunjungi kota-kota pelabuhan (kota bawah) di provinsi Guandong dan Fujian serta kota-kota pantai Asia Tenggara mengatakan ruko merupakan "landmark" kota-kota tersebut. Bahkan penulis Prancis, Viaro (1992), sedikit meragukan apakah ruko memang berasal dari Tiongkok. Dia memberikan hipotesis bahwa ruko adalah percampuran arsitektur akibat dari perdagangan di sepanjang pantai antara Tiongkok dan Asia Tenggara oleh orang Barat, Cina dan penduduk setempat.

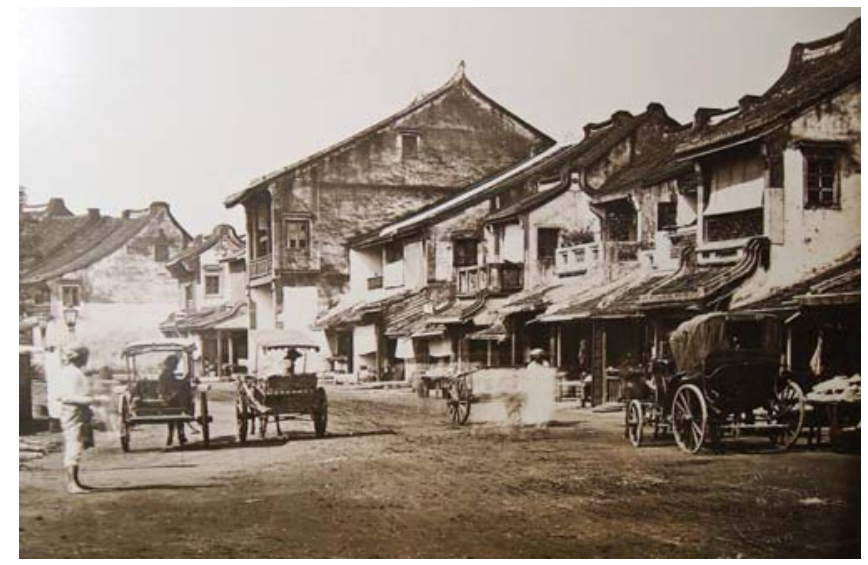

Gambar 2 Suasana Pintu Kecil sekitar 1872.

(Merrillees, 2010:81) 
Ini sangatlah berbeda dengan nilai-nilai arsitektur tradisi dari Tiongkok yang cenderung bersifat megah dan besar (the grand architectural tradition). Nilai arsitektur tradisi Tiongkok meliputi struktur imperial dari Tiongkok Utara yang dapat dikatakan tidak berhubungan langsung dengan kebudayaan mayoritas rakyat Tiongkok (Handinoto, 2010). Karakter bangunan Cina di kawasan Nusantara, khususnya di Jakarta, berbeda jauh dengan di Cina Daratan.

Hidayat (2009) dalam penelitiannya mengatakan:

"Antipati terhadap etnis Tionghoa pada masa pemerintahan Orde Baru sesungguhnya merupakan warisan panjang (dampak pada waktu yang lama) politik pecah-belah pemerintah kolonial Belanda. Sebelum abad ke 19, relasi antara etnis Tionghoa dan etnis lain di Indonesia adalah relasi damai dalam kondisi setara. Akulturasi dan asimilasi budaya terjadi secara alami, tanpa dikonstruksi atau dipaksakan oleh pihak penguasa, tetapi atas dasar simbiosis mutualisme. Pada masa penjajahan, ketika Belanda membagi penduduk jajahan dalam kategori-kategori yang menempatkan etnis Tionghoa di atas pribumi, relasi damai ini berubah menjadi sentimen dan antipati.”

Manusia yang hidup dalam lingkungan yang berbeda budaya membutuhkan adaptasi. Perubahan budaya dari seseorang yang beradaptasi merupakan sebuah cara menyesuaikan diri dengan lingkungan budaya yang baru. Adaptasi sebagai keharusan bagi seseorang pendatang terhadap budaya setempat. Dalam Gudykunst dan Kim disebutkan bahwa proses sosialisasi adaptasi membutuhkan belajar dan memperoleh semua yang membuat manusia hidup pada lingkungan yang lain. Seseorang yang hidup dalam masyarakat akan terjadi suatu proses enkulturasi dan akulturasi. Enkulturasi adalah proses yang mempertalikan individu yang berkembang dengan konteks budaya mereka. Konsep enkulturasi adalah pewarisan budaya mendekati pewarisan biologis, misalnya dengan proses pembelajaran dari orangtua, orang dewasa. Enkulturasi dapat dikatakan berhasil jika seseorang mewarisi budaya baik bahasa, nilai-nilai, maupun acara ritual. Dapat dikatakan sebagai pewarisan budaya kepada seseorang terutama kepada seorang anak sehinga berperilaku sesuai dengan budayanya.

Sedangkan akulturasi adalah suatu proses yang merujuk pada perubahan budaya dan psikologis karena perjumpaan dengan orang yang berbudaya berbeda. Proses ini memungkinkan budaya dan kelompok etnis menyesuaikan diri dengan budaya yang lain. Perubahan ini dapat merujuk kepada sikap, nilai, dan jati diri. Adaptasi dan akulturasi dapat terjadi biasanya pada kaum pendatang, mereka menyesuaikan diri dengan budaya setempat (budaya baru) yang sebelumnya tidak diketahui. Nadyadilaga (2009) memberikan sebuah bentuk diagram Sistem Sosial yang terdiri dari tiga unsur (TRIO).

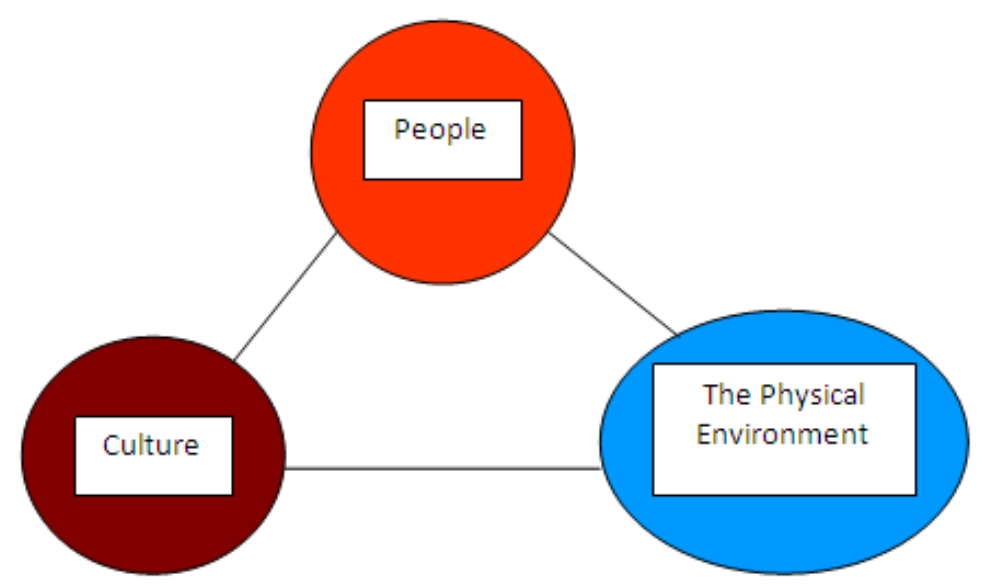

Gambar 3 Diagram Sistem Sosial

(Sumber: Nadyadilaga, 2009) 
Jika dilihat arsitektur sebagai wujud dari hasil karya manusia dapat masuk dalam urutan terakhir dari unsur kebudayaan menurut Koenjtaraningrat. Arsitektur bangunan tidaklah lepas dari pengaruh kebudayaan setempat. Pengaruh dapat dari berbagai cara yang dalam ilmu antropologi dikenal sebagai proses akulturasi. Proses akulturasi atau culture contact dapat terjadi jika suatu kelompok manusia dengan suatu kebudayaan asing yang berbeda sedemikian rupa, sehingga lambat laun diterima dan diolah ke dalam kebudayaan sendiri tanpa menyebabkan hilangnya kepribadian kebudayaan itu sendiri (Nadyadilaga (2009). Untuk itu akulturasi dapat dikatakan sebagai proses jalan tengah dari sebuah konfrontasi, isolasi, absorpsi yang menyatu (fusi) dalam jangka waktu tertentu. Proses akulturasi dapat dibagi menjadi (1) penyesuaian (assimilated) merupakan sebuah model akulturasi antara dua budaya atau lebih yang menghadirkan suatu penyesuaian baru karena adanya faktor kebutuhan; (2) penyesuaian (Integrated) model akulturasi antara budaya-budaya yang membentuk budaya baru; (3) pemilihan (Separated) model yangmenekankan pada ekletikvitas dalam prosesnya; (4) peminggiran (Marginalized) model akulturasi dengan faktor terbesar budaya tersebut akan menggeser budaya kecil yang ada di sekitarnya (Nadyadilaga, 2009).

Daerah Pecinan dari zaman dulu sudah sangat padat. Ruko (shop houses) sebagai perpaduan antara daerah bisnis di lantai bawah dan daerah tempat tinggal di lantai atas merupakan ide pemecahan masalah yang baik untuk menanggulangi kepadatan daerah tersebut (Handinoto, 2009). Pada lantai satu terdapat aktivitas komersial sedangkan aktivitas hunian di lantai atasnya. Denah rumahnya sangat panjang dengan tampak depan (fasade) yang sempit. Ruko dibangun bersebelahan dengan tembok bersama antara rumah yang satu dengan yang lain. Organisasi ruang seperti ini berdasarkan kepercayaan Fengshui agar penghuninya selalu beruntung.

( Khol, 1984)

Cikal bakal tipe rumah rakyat seperti ini banyak ditemukan di kota-kota perairan Cina Selatan.

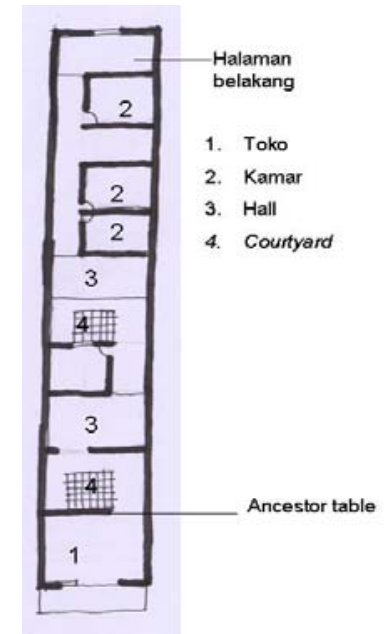

Gambar 4 Denah sebuah ruko di Fukien dengan denah masih satu lantai (Disketsa kembali )

Rumah Toko atau shop house dapat dikatakan bentuk yang paling umum pada kota urban di kawasan Asia Tenggara yang pada masa-masa awal kota komersial berkembang sebagai akibat perdagangan dibangun dengan menggunakan grid yang membentuk blok (Nasution, 2009).

Dalam meninjau sebuah arsitektur, tampilan luar bangunan yang disebut fasade adalah bagian yang paling mudah dikenali dalam melihat style sebuah bangunan. Atau dapat dikatakan sebagai wajah dari bangunan tersebut. Bagian fasade bangunan ini juga sering disebut tampak kulit luar ataupun wajah bangunan. Fasade bangunan ini merupakan yang paling sering diberi penilaian oleh para 
pengamat tanpa memeriksa terlebih dahulu keseluruhan bangunan baik di keseluruhan sisi luar bangunan maupun pada bagian dalam bangunan. Penilaian tersebut tidak hanya dilakukan oleh para arsitek tetapi juga masyarakat awam (Prijotomo, 1987). Sebuah fasade bangunan dapat dilihat komposisinya dengan pertimbangan elemen-elemen bangunan yang fungsional seperti jendela, pintu, sun shading, bidang atap. Prinsip ini terkait dengan prinsip-prinsip desain seperti keseimbangan, kesatuan, harmonis, proporsi, pengulangan (irama).

Atap dapat dikatakan sebuah elemen arsitektur yang mempunyai ciri khas yang kuat dalam sebuah karya budaya. Karena atap yang mempunyai ciri khas yang kuat, gaya arsitektur sebuah bangunan dapat langsung dipahami. Pada bangunan Cina, atap mempunyai ciri khas tersendiri dengan bentuk pelana yang khas melengkung pada ujungnya (Gambar 5). Atap dengan ornamen yang melengkung pada ujungnya melambangkan ekor walet sebagai simbol kemakmuran.

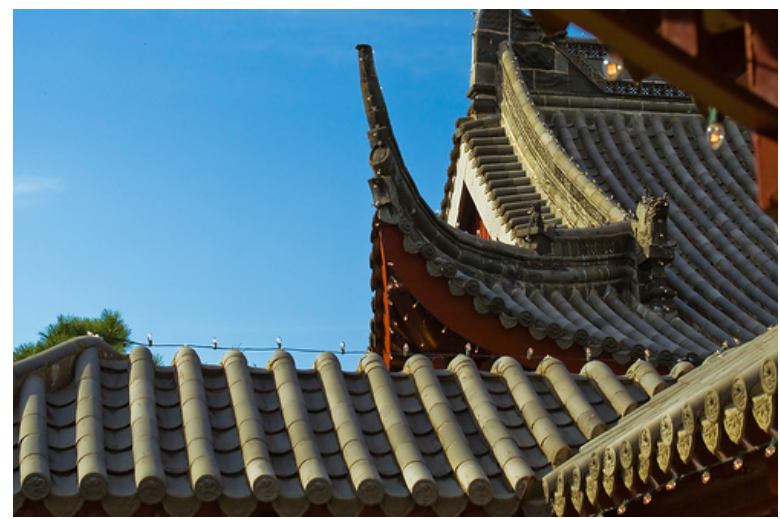

Gambar 5 Ujung Atap yang Mencuat seperti Ekor Burung Walet di Cina Daratan (Knapp, 2010:262)

Atap Cina sering disebut atap lengkung (the curved roof); atau dalam istilah Cina disebut Chuche. Chu-che dapat diartikan sebagai raise and depress, dengan perbandingan 1:2 untuk rumah kecil dan 2:3 untuk bangunan besar. Beberapa jenis atap yang ditemukan di Cina Daratan antara lain seperti pada Gambar 6.

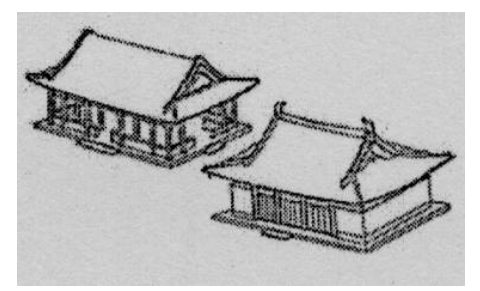

Atap model Hsuan Shan jarang dipakai di Indonesia

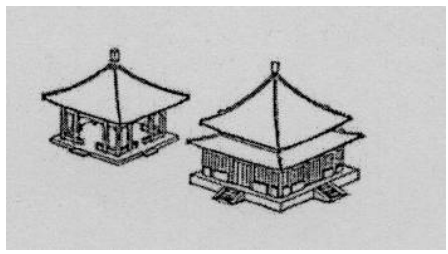

Atap Model Tsuan Tsien ,tidak pernah dipakai di Indonesia

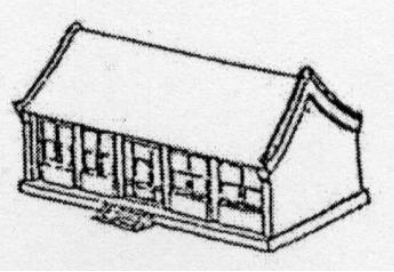

Atap Model Ngang Shan, paling banyak dipakai di Indonesia.

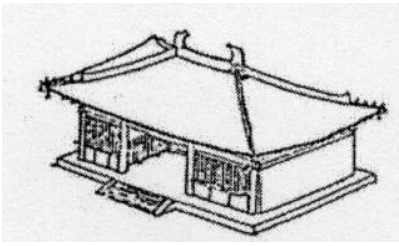

Atap model Wu Tien, jarang di jumpai di Indonesia Gambar 6 Berbagai model atap yang menjadi bagian arsitektur Cina (Julianto, 2008:74) 
Namun pada ruko Cina peranakan yang ada di Batavia pada abad ke-19 banyak terdapat pengaruh Eropa. Pengaruh Eropa disebabkan di sisi kiri dan kanan juga terdapat ruko yang lain, sehingga pilihan atap yang banyak dipakai adalah atap pelana yang dalam arsitektur Cina disebut dengan istilah atap Ngang Shan. Keterbatasan lahan membuat pilihan atap jenis ini yang paling sesuai beradaptasi dengan lingkungan. Sebuah ruko cina peranakan dengan tipe atap Ngang Shan dapat dilihat di kawasan Senen. (Gambar 7)

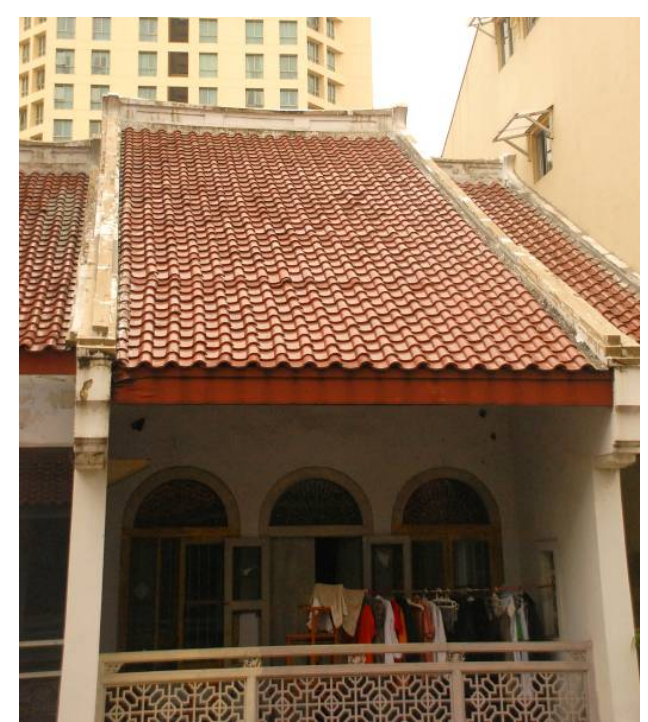

Gambar 7 Tipe atap Ngang Shan (atap pelana) karena keterbatasan lahan di kiri dan kanan kavling

(Foto: Christianto R, 2010)

Karena tipografi Indonesia yang terletak di negara tropis, model jendela dapat berupa jendela krepyak (berjalusi) agar udara yang panas dapat mengalir serta menyejukkan udara di dalam rumah.

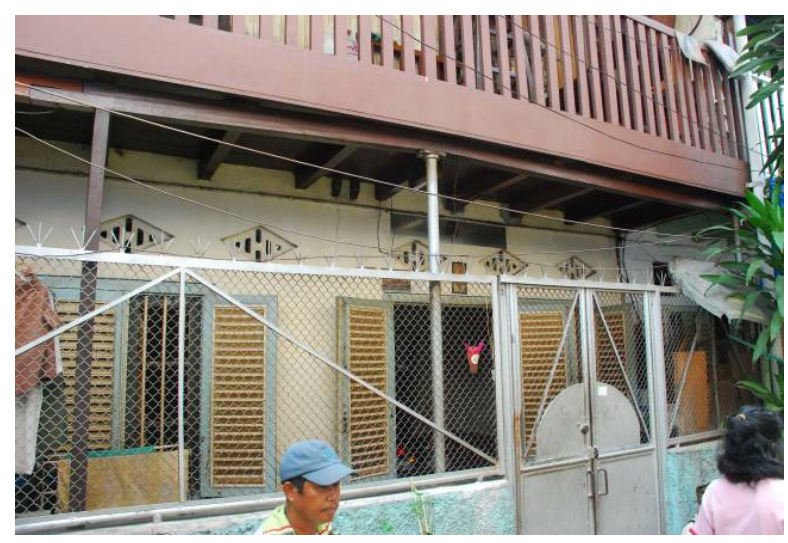

Gambar 8 Daun jendela berjalusi untuk mengantisipasi udara panas

(Foto: Christianto R, 2009)

Jendela yang dipakai di ruko cina peranakan di Indonesia merupakan akulturasi dari jendela Cina, Eropa, dan Melayu. 


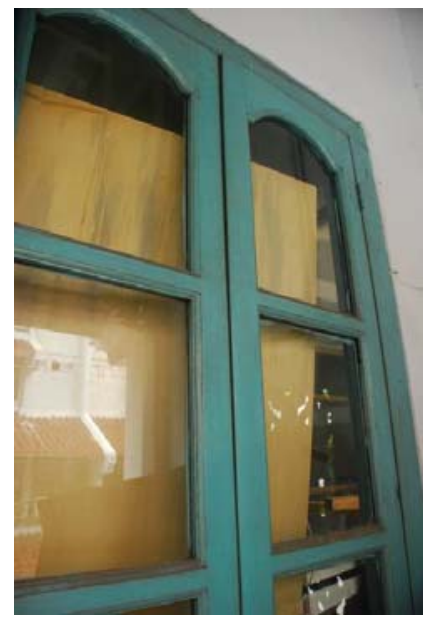

Gambar 9 Jendela dengan sedikit detail Belanda (Foto: Christianto R, 2010)

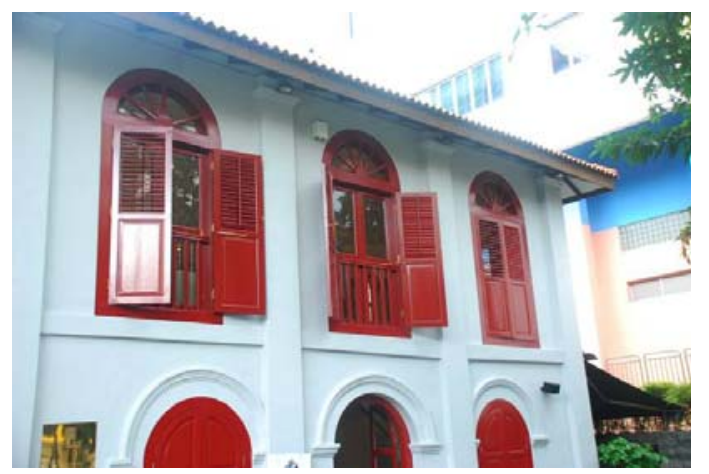

Gambar 10 Perpaduan Gaya Cina Peranakan, Eropa, Melayu di Singapura (Foto: Christianto R, 2009)

Jika diteliti secara mendalam, rumah cina peranakan lebih terlihat merakyat daripada arsitektur rumah cina di daerah asalnya. Masyarakat Cina yang datang ke Asia Tenggara dari Fujian, Cina Selatan, berprofesi sebagai pedagang dan nelayan. Pada masa kolonialisme oleh bangsa Eropa, pengaruh Eropa, dalam hal ini Belanda, cukup terlihat. Belanda -bangsa yang memegang peranan penting lingkar kekuasaan- telah mengkavlingkan tanah-tanah di Batavia. Bentuk kavling tanah di Batavia lebih cenderung berkiblat pada kavling di kota, misalnya Amsterdam.

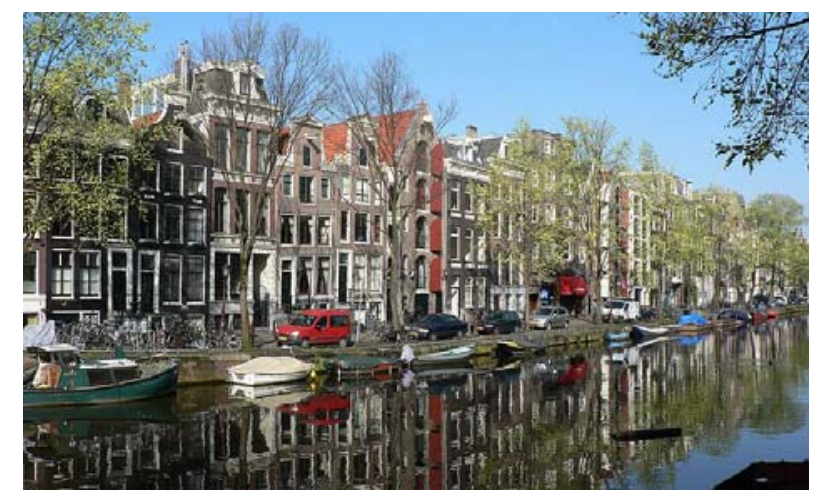

Gambar 9 Gedung-gedung di kota Amsterdam, Belanda, dengan fasade yang sempit (Sumber: Clenet, 2006) 
Penjajah Belanda mengatur perkampungan cina di dalam berbagai kawasan berdasarkan ragam aktivitas ekonomi. Para pedagang menempati sisi jalan utama; sedangkan tukang daging, nelayan, pedagang kelontong, tukang sofa dan lain-lain menempati sisi jalan yang lain. Pada 1717 otoritas pemerintah memperbolehkan menambahkan cerobong asap bovenstoep di rumah mereka. Setelah 1761 rumah dapat menggunakan model atap cina dan teras yang dalam pada desain serta konstruksi rumah toko mereka. (Widodo, 2004)

Ini hampir tidak ditemukan pada arsitektur bangunan asli di Cina daratan. Bentuk atap yang diadaptasi lebih banyak berbentuk Ngang Shan, sebagai atap yang dapat beradaptasi dengan sempitnya kavling yang terjadi di kawasan pecinan yang padat penduduknya. Jika dilihat pada proses pembangunan kota Batavia pada awal J. P. Coen membawa 100 orang Cina dari Banten untuk membangun Batavia, hal itu memperlihatkan juga terjadinya adaptasi dan akulturasi bangunan Eropa yang sempit dan berbentuk memanjang seperti kota-kota tua di Eropa. Pada kasus ini latar belakang J. P. Coen sebagai seorang berkebangsaan Belanda turut mewarnai karakter fasade bangunan Pecinan di Batavia. Lebih lanjut Powell (2004:14) menyatakan:

"The Shop house plans probably originated from the godowns used by the Dutch in the port of Bencoolen, and they were hybrid of the row houses of Amsterdam combined with the domestic buildings of Southern China. The plans were narrow and deep, the deeper houses employing at least one and often two lightweels to provide daylight and ventilation."

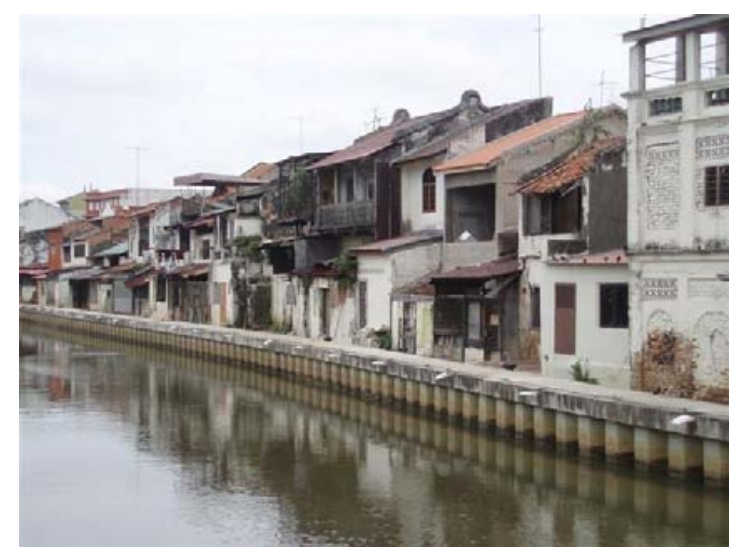

Gambar 10 Ruko-ruko Cina yang berada di tepi sungai Ciliwung

(Foto: Christianto R, 2009)

Jika diteliti, ruko sebagai sebuah karya budaya sangatlah dipengaruhi oleh berbagai faktor yang justru bukanlah merupakan hal-hal yang berkaitan dengan desain. Karakter ruko tidaklah berbentuk grand arsitektur seperti peninggalan bangunan di kota-kota besar di Cina seperti Beijing, Shanghai, dan lainnya. Tidak seperti bangunan hunian di Fujian, Guandong, Cina Selatan yang lebih berbentuk bujursangkar dengan beberapa courtyard, ruko di Batavia mempunyai bentuk denah yang memanjang ke belakang serta mempunyai fasade yang sempit. Bentuk kavling yang berdempet dengan bangunan tetangga serta berbentuk grid teratur ini disebabkan pengaruh Belanda sebagai pemegang kekuasaan pada abad ke-19. Hal tersebut turut memengaruhi pengaturan pecinan mempunyai karakter yang hampir sama dengan kota-kota di Belanda.

\section{SIMPULAN}

Konsep bangunan ruko, yang ada pada zaman dulu dengan sekarang dapat dikatakan tidaklah berubah secara signifikan. Konsep bertempat tinggal sekaligus menjadi tempat usaha merupakan 
konsep yang cukup dapat diterima sampai saat ini karena keterbatasan lahan. Untuk itu akulturasi dapat dikatakan sebagai proses jalan tengah dari sebuah konfrontasi, isolasi, dan absorpsi yang menyatu (fusi) dalam jangka waktu tertentu yang meleburkan bentuk banguan ruko pada masa-masa awal menjadi bentuk bangunan ruko seperti sekarang.

\section{DAFTAR PUSTAKA}

Clenet, P. (2006, May). File: Amsterdam 052006.jpg. Diakses 28 Mei 2013 dari http://commons.wikimedia.org/wiki/File:Amsterdam_052006.jpg

Handinoto \& Soehargo. (1996). Perkembangan Kota dan Arsitektur Kolonial Belanda di Malang, Surabaya: Universitas Petra.

Hidayat, J. (2009, Des.). Paradigma individual konstruksi identitas dalam desain hibrid: ilusi dimensi tunggal identitas yang bersifat kolektif, studi kasus: desain rumah Tionghoa peranakan. ITB J.Vis Art \& Des, 3(1), 25-42.

Julianto, I. (2008). Komunitas Lintas Budaya Indonesia. Peranakan Tionghoa Indonesia. Jakarta: Intisari.

Khol, D. G. (1984). Chienese Architecture in the Starits Settlements and Western Malaya; Temples, Kongis and Houses. Kuala Lumpur: Henemann Educational Books (Asia).

Knapp, R. G. (2010). Chinese Houses of Southeast Asia. Singapore: Tuttle Publishing.

Merrillees, S. (2010). Batavia in Nineteenth Century Photographs, Singapore: Editions Didier Millet.

Nadyadilaga, A. R. (2009). Bahan Perkuliahan Master Desain I. Jakarta: Program Master Desain Produk Universitas Trisakti.

Nasution, K. S. (2009). Heritage House of Penang. Singapore: Marshall Cavendish Editions.

Powell, R. (2004). Singapore Architecture. Singapore: Periplus.

Prijotomo, J. (1987). Komposisi Olah Tampang Arsitektur Kampung Surabaya. Surabaya: Pusat Penelitian Institut Teknologi Sepuluh November.

Salmon, Cl., \& Lombard, D. (1985). Les Chinois de Jakarta-Temple et Vie Collective, Secmi, Gue'ret. Jakarta: Cipta Loka Caraka.

Stamet Ahmad Yani Semarang. (n.d.). Monsun. Diakses 28 Mei 2013 dari http://www.cuacajateng.com/monsun.htm

Viaro, A. (1992). Is The Chinese Shophouse Chinese? (Draft English translation from "Le Compartiment Chinois est-il Chinois?”) Marseille: Parentheses.

Widodo, J. (2004). The Boat and The City, Chinese Diaspora and Architecture of Southeast Asian Coastal Cities. Singapore: Marshall Cavendish International. 